\title{
Las funciones de la escuela secundaria brasileña en el contexto del ajuste neoliberal y de
} la crisis del capital

\author{
Neide de Almeida Lança Galvão Favaro ${ }^{1}$ \\ neidegafa@hotmail.com \\ http://orcid.org/0000-0003-0569-7225 \\ Priscila Semzezem ${ }^{1}$ \\ priscilasemzezem@ hotmail.com \\ http://orcid.org/0000-0002-5410-2585 \\ Cleissiane Aguido Gotardo 1 \\ cleissiane@hotmail.com.br \\ http://orcid.org/0000-0002-9436-3827 \\ ${ }^{1}$ Universidade Estadual do Paraná \\ Campus Paranavaí, Brasil
}

Recibido: 09/04/2020 Aceptado: 22/05/2020

\begin{abstract}
Resumen
Brasil sufre ataques brutales contra los derechos de la clase trabajadora. Entre ellos está la Ley $\mathrm{N}^{\circ}$ 13.415/2017, que cambia la escuela secundaria brasileña, impuesta por encima de manifestaciones y resistencias. Dada la importancia de su comprensión, esta investigación está basada en la referencia del materialismo histórico y analiza las funciones que asume la escuela secundaria con esa normativa, insertada en el marco de las políticas neoliberales y en medio de la fase actual de la reestructuración del capital mundial. En las relaciones sociales contradictorias típicas del capital monopolista, en el que Brasil ocupa una posición subordinada en la división internacional del trabajo, la flexibilización de la escuela secundaria es una de las estrategias de privatización de la educación pública y del control ideológico y político para la conformación de la clase trabajadora. Ello asegura la expansión de las tasas de ganancia del capital, necesarias para su reproducción por medio de crisis periódicas profundizadas desde la mitad de la década de 1970, promoviendo la degradación de la formación humana y su subsunción al capital.
\end{abstract}

Palabras clave: Producción Flexible. Neoliberalismo. Escuela Secundaria.

\section{As Funções do Ensino Médio Brasileiro no Âmbito do Ajuste Neoliberal e da Crise do Capital}

\section{Resumo}

O Brasil vivencia ataques brutais aos direitos da classe trabalhadora. Dentre eles situa-se a Lei $\mathrm{n}^{\mathrm{o}}$ 13.415/2017, que altera o Ensino Médio brasileiro, imposta à revelia de manifestações e resistências. Diante da importância de seu entendimento, esta pesquisa, pautada no referencial do materialismo histórico, analisa as funções que o Ensino Médio assume com essa normativa, inserida no arcabouço das políticas neoliberais, em meio à atual fase de reestruturação do capital mundial. Nas contraditórias relações sociais típicas do capital monopolista, em que o Brasil ocupa uma posição subalterna na divisão internacional do trabalho, a flexibilização do Ensino Médio figura dentre as estratégias de privatização da educação pública e de controle ideológico 
e político para a conformação da classe trabalhadora. Assegura-se, assim, a ampliação das taxas de lucro do capital, necessária para sua reprodução mediante as crises periódicas aprofundadas a partir de meados da década de 1970, promovendo a degradação da formação humana e sua subsunção ao capital.

Palavras-chave: Produção Flexível, Neoliberalismo, Ensino Médio.

\title{
Functions of brazilian high school in the context of neoliberal adjustment and the capital crisis
}

\begin{abstract}
Brazil experiences brutal attacks on working class rights. Among these attacks there is the Law number 13,415/2017, which changes the Brazilian High School, imposed behind manifestations and resistances. Given the importance of its understanding, this research is based on the reference of historical materialism and analyzes the functions that high school assumes with this normative, inserted in the neoliberal policies framework, amid the current phase of world capital restructuring. In the contradictory social relations typical of monopoly capital, in which Brazil occupies a subordinate position in the international division of labor, the flexibility of high school is among the strategies for privatizing public education and for ideological and political control to make the working-class conformation. Hence, it ensures the expansion of the profit rates of capital, what is necessary for its reproduction through periodic crises deepened from the middle 1970s, promoting the degradation of human formation and its subsumption to capital.
\end{abstract}

Keywords: Flexible production. Neoliberalism. High School.

\section{Introdução}

A posição subalterna que o Brasil ocupa na divisão internacional do trabalho tem determinado as características do projeto nacional adotado, afetando o desenvolvimento da ciência e da tecnologia, bem como o direcionamento da formação humana no país. Isto fica expresso nas políticas sociais e educacionais brasileiras.

$\mathrm{Na}$ atual conjuntura, essa posição nacional tem surtido graves efeitos para a classe trabalhadora, em virtude das condições de acumulação do capital diante das intensas e frequentes crises mundiais. As soluções acionadas para seu enfrentamento resultam em medidas que incidem sobre a vida humana, pois destituem direitos conquistados historicamente.

A promulgação da Lei n 13.415, em 16 de fevereiro de 2017 (Brasil, 2017a), a chamada Reforma do Ensino Médio, representa um desses ataques aos direitos da classe trabalhadora, em relação à educação pública e laica. Sua aprovação foi alvo de várias resistências e críticas de representantes dos interesses populares.

Frente a tal contexto, objetiva-se analisar as funções que o Ensino Médio assume com essa normativa legal, inserida no arcabouço das políticas neoliberais e no âmbito da atual fase de reestruturação do capital. A reflexão é pautada na perspectiva do materialismo histórico e 
Neide de Almeida Lança Galvão Favaro, Priscila Semzezem, Cleissiane Aguido Gotardo

tem como pressuposto a necessidade de apreensão das especificidades da atual relação socioeconômica, pois concebe que as diretrizes educacionais estão condicionadas ao movimento mais amplo do capital na recente fase monopolista. Esse percurso teórico-metodológico permite ir além da esfera política e da constatação de seus efeitos, ao vislumbrar suas causas mais profundas e, deste modo, auxiliar no enfrentamento de suas consequências para as juventudes brasileiras.

Face a esta premissa, é mister considerar que a corrente reforma do Ensino Médio brasileiro é resultado de um amplo processo, que envolve questões econômicas, políticas e sociais, não se limitando a necessidades e interesses pedagógicos. A compreensão de seus objetivos e implicações demanda, por conseguinte, o estudo de seus determinantes estruturais, que é o tema da primeira parte desta exposição. Na seção seguinte, identificam-se as funções que o Ensino Médio assume no Brasil a partir da Reforma de 2017 e suas consequências sociais e humanas, diante das relações típicas do capital em seu estágio atual.

\section{A Reforma do Ensino Médio e seus Fundamentos Estruturais}

A Reforma do Ensino Médio foi proposta pelo governo de Michel Temer (2016-2018) e aprovada pela Lei no 13.415, no dia 16 de fevereiro de 2017 (Brasil, 2017a), sob vários protestos. A necessidade inicial que se coloca é desvelar as causas que geraram tal reformulação, mesmo diante da intensa resistência de estudantes, professores e pesquisadores.

Isto requer a apreensão das políticas públicas no interior de sua vinculação a determinado projeto de desenvolvimento adotado pelo Estado que, no capitalismo, desempenha a função de definir e implementar as medidas necessárias à expansão e acumulação do capital. Segundo Mészáros (2002, p. 121), em qualquer de suas formas, o princípio que o orienta "é o seu papel vital de garantir e proteger as condições gerais da extração da mais-valia do trabalho excedente". Suas políticas expressam, por conseguinte, demandas e interesses específicos, que estão atrelados à conjuntura que conforma a sociabilidade existente, voltada à defesa do capital.

Considerando a relação social do capital, fundada na propriedade privada dos meios de produção e caracterizada por classes sociais distintas, é frequente a existência de divergências radicais, tendo em vista o confronto de seus interesses. Esta luta de classes é fruto das relações econômicas instituídas e, por isto, é a partir de suas contradições que se revela a base material que sustenta e direciona as políticas públicas implantadas pelo Estado. 
Cabe especificar a função do Estado capitalista para assegurar as taxas de lucros, o que traz consequências diretas aos trabalhadores. Tumolo (2003) explica sua atuação: primeiro, através do financiamento parcial ou total para a construção de infraestrutura, isenção de impostos, entre outras medidas; segundo, com a destinação de volumosos aportes estatais para socorrer as crises; e terceiro, a partir da utilização de recursos para outras funções, como as de coerção e de repressão. Na contemporaneidade, há a sua desresponsabilização em relação às políticas sociais, como educação, seguridade social, entre outras.

Isto tem ocorrido mediante a intensificação das crises mundiais do capital, que exige, para sua recuperação, respostas adequadas ao caráter que configura seu estágio atual. Este cenário se estende desde meados da década de 1970, demandando ajustes econômicos e políticos para sua superação e para a retomada do crescimento econômico.

Os sinais de uma grave crise de acumulação eram em toda parte aparentes. O desemprego e a inflação se ampliavam em toda parte, desencadeando uma fase global de 'estagflação' que duraria por boa parte dos anos 1970. [...]. O liberalismo embutido que gerara altas taxas de crescimento pelo menos nos países capitalistas avançados depois de 1945 estava claramente esgotado e deixara de funcionar (Harvey, 2008, p. 22).

Esses fatores assinalaram a incapacidade da continuidade do padrão de organização e de gestão da produção então vigente, denominado fordista-keynesiano. Difundiram-se, na produção, os pressupostos do toyotismo, no qual a linha de montagem é substituída pelas células de produção, pelo trabalho coletivo e pelo trabalhador polivalente. A produção em massa, típica do taylorismo e fordismo, cede lugar ao atendimento da demanda, permitindo a diminuição do espaço físico e do número de trabalhadores, flexibilizando as relações de trabalho, em virtude das inovações científico-tecnológicas.

Além disso, Gounet (1999) destaca que este novo modo de organizar a produção exige ainda mais do trabalhador, em relação ao fordismo, pois há uma intensificação do trabalho. Neste processo, um trabalhador chega a operar cinco máquinas ao mesmo tempo e, para essas ações, faz-se necessário que ele seja polivalente.

Os efeitos para a classe trabalhadora são devastadores, pois o trabalho é terceirizado, ampliando os contratos temporários e introduzindo o trabalho intermitente, o que permite aprofundar as condições de exploração. No toyotismo, “a política básica é usar o mínimo de operários e o máximo de horas extras" (Gounet, 1999, p. 30). A exploração do trabalho adquire 
Neide de Almeida Lança Galvão Favaro, Priscila Semzezem, Cleissiane Aguido Gotardo

novos contornos e o trabalhador atinge a exaustão, o que tem acarretado consequências prejudiciais a sua saúde. O desemprego e a miséria intensificam-se e a degradação do trabalho assola a classe trabalhadora.

O toyotismo, por se caracterizar como um regime flexível, permite superar melhor as eventuais crises econômicas. Tumolo (2002) explica que este modelo de acumulação do capital foi uma resposta à crise de superacumulação de 1973, e que ele passou a conviver com o modelo predominante anterior, taylorista-fordista.

Essas mudanças econômicas ocorreram em sintonia com a implementação da ideologia neoliberal, voltada para atender aos interesses do capital, de superação de suas crises. O neoliberalismo se iniciou com Pinochet, no Chile, em 1975, e foi efetivamente implementado com Margareth Thatcher, na Inglaterra, em 1979, expandindo-se com Ronald Reagan, nos Estados Unidos, em 1980. Ele resulta em um processo de desresponsabilização do Estado na área social, cujos serviços convertem-se em mercadorias, com o objetivo de recuperação das taxas de lucro do capital. Pode-se “interpretar a neoliberalização seja como um projeto utópico de realizar um plano teórico de reorganização do capitalismo internacional ou como um projeto político de restabelecimento das condições da acumulação do capital e de restauração do poder das elites econômicas" (Harvey, 2008, p. 27).

Esse processo ficou mais visível no Brasil a partir da década de 1990, quando o neoliberalismo foi aprofundado no governo nacional, reconfigurando a articulação entre economia e Estado. O país alinhou-se, naquele momento, às medidas neoliberais destinadas à América Latina, que foram gestadas pelos países centrais, a partir do Consenso de Washington, em 1989. Recomendaram-se os denominados “ajustes" estruturais e fiscais à periferia do sistema, a fim de atender aos interesses do capital mundial. Para reestabelecer as taxas de acumulação, na divisão internacional do trabalho, serviços e produtos vem sendo mercantilizados e privatizados, sob a justificativa ideológica da eficiência e da qualidade.

Desponta aí uma das características do novo padrão de acumulação do capital, que é a mundialização do capital financeiro. Esta se completou nos anos de 1980, intensificando o deslocamento da acumulação para os ganhos financeiros, em detrimento da esfera produtiva (Chesnais, 1999).

No Brasil, segundo Lima (2019), defende-se o ajuste fiscal para o pagamento da dívida externa, movimento que destina os recursos direto para o capital internacional. Canalizam-se 
assim volumosos aportes públicos para o setor da dívida pública. Este processo pode ser visualizado através do Gráfico 1 . O valor executado no orçamento brasileiro, durante o ano de 2019, foi de R\$2,711 trilhões. A maior parte destes recursos foram direcionados ao capital financeiro, através do pagamento da dívida pública, em um montante de R $\$ 1,038$ trilhões. A educação, por sua vez, só teve aporte de 3,48\% do total de recursos.

\section{Gráfico 1 - Orçamento Federal Executado (Pago) 2019}

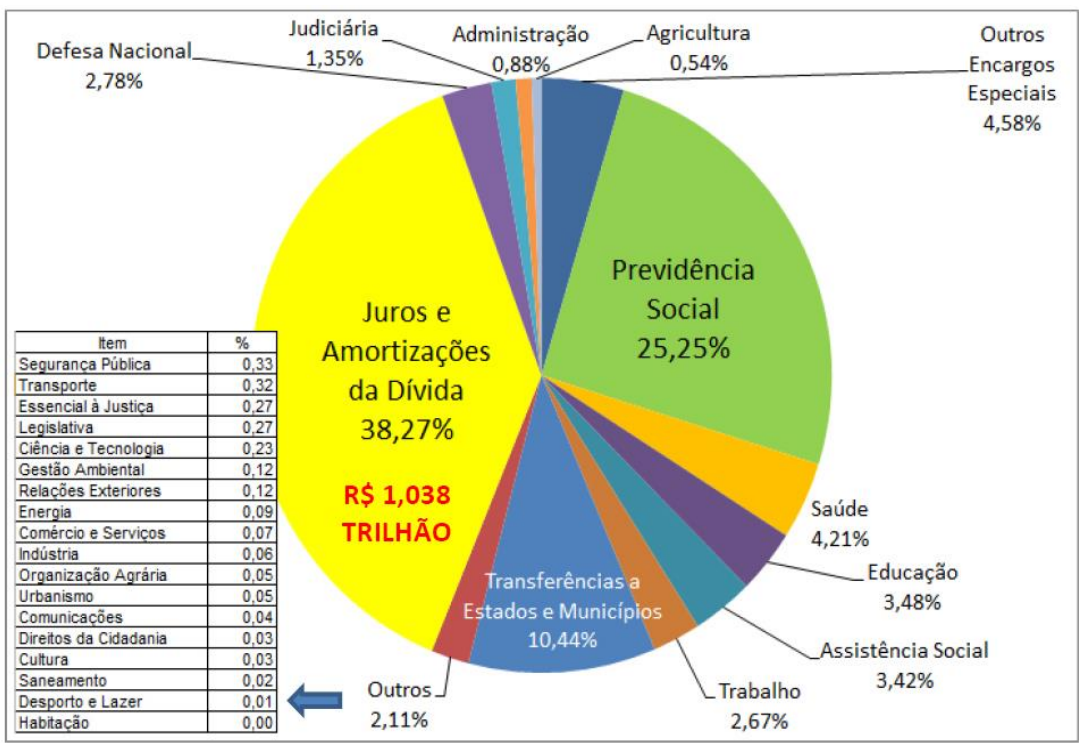

Fonte: Auditoria Cidadã da Dívida (2020).

Nos países periféricos, como o caso do Brasil, “a dívida pública alimenta continuamente a acumulação financeira por intermédio das finanças públicas” (Chesnais, 2005, p. 41). O autor demonstra ainda que, para assegurar o desenvolvimento do capital financeiro, são operadas também políticas de ajuste estrutural, austeridade fiscal, liberalização e privatização, que rebatem diretamente no cotidiano da vida da classe trabalhadora, já que nesses processos os direitos sociais conquistados historicamente são colocados em xeque.

Por consequinte, uma determinação deste processo é a restrição de orçamento e recursos das políticas sociais, pois a prioridade da função estatal é assegurar o pagamento da dívida. A forma mais radicalizada deste processo, na atualidade brasileira, expressa-se pela Emenda Constitucional (EC) $n^{\circ}$ 95/2016, que congelou investimentos públicos por vinte anos. Ela “revoga a vinculação das despesas com saúde e educação aos percentuais da receita líquida da União" (Lima, 2019, p. 518). Entre as justificativas apontadas para efetivação da EC 95 seria a retomada do crescimento do Produto Interno Bruto (PIB), entretanto, mesmo depois aprovada, 
os dados expressos pelo Instituto Brasileiro de Geografia e Estatística sobre o PIB demonstram que, em 2017 e 2018, manteve-se o crescimento de 1,3\%; já em 2019, cresceu apenas 1,1\% (Cucolo \& Pamplona, 2020), o que em si justificaria um questionamento social para tal medida.

No setor social, o resultado está sendo o atendimento focalizado aos mais pobres, promovendo "o corte na alocação de verbas públicas para as políticas públicas e o favorecimento da movimentação do setor privado nas áreas de maior lucratividade” (Lima, 2019, p. 518). O saldo brasileiro tem sido o baixo investimento na educação e nas áreas sociais, o que permite apontar que o capital avança para assegurar a sua reprodução.

Dentre os efeitos perversos deste arranjo político e econômico para a classe trabalhadora, destacam-se o seu enfraquecimento coletivo, a competição, a meritocracia e a responsabilização individual. Elementos que contribuem para "novos conformismos sociais, ou seja, tornando naturais condições perversas do mercado, como a incerteza do futuro profissional e a precarização do trabalho" (Zibas, 2005, p. 27).

É neste contexto que o Estado aciona a educação, a fim de contornar os problemas sociais insolúveis, típicos da lógica interna da relação do capital. O discurso da flexibilização ilude a população com a ideologia da empregabilidade, e a mistificação burguesa inclui a defesa do empreendedorismo como solução ao desemprego, delegando ao indivíduo a responsabilidade pela sua condição social. Devido à lógica estrutural do capital e à concorrência do mercado, a tendência perversa é conduzi-lo ao fracasso. Isto porque, nas relações produtivas reais, o que se observa é o crescimento do desemprego nos países que flexibilizaram o trabalho (Netto \& Braz, 2012).

Em face da configuração atual da relação do capital, assentada na reestruturação produtiva e no arcabouço político e ideológico neoliberal, é difundida a ideia da necessidade de outra maneira de formar a força de trabalho, supostamente mais ampla e qualificada. Motta, Leher e Gawryszewski (2018) revelam como a educação é mobilizada para essa função, por intermédio da descaracterização da educação pública, desconstruindo a sua imagem e a de seus trabalhadores, os professores, a fim de transferir a esfera educacional para o controle privado. Para isto, acionam-se os meios de comunicação para conformar a opinião pública e difundir a pedagogia do capital. 
A narrativa amplamente difundida pelas frações dominantes locais, em consonância com as proposições dos organismos internacionais destacadamente a Unesco e, sobretudo, a Organização para a Cooperação e o Desenvolvimento Econômico (OCDE) e o Banco Mundial - está centrada na tese de que a formação escolar atual não condiz com as expectativas da sociedade em geral: não é atraente ao jovem e não condiz com a 'sociedade do conhecimento' (Motta, Leher \& Gawryszewski, 2018, p. 315, grifos dos autores).

Esse argumento tem sustentado as reformas do país no campo da educação desde a década de 1990, a fím de atender à lógica do mercado, resultando em políticas educacionais que viabilizaram as condições para tornar a educação uma mercadoria rentável. A promulgação da Lei de Diretrizes e Bases da Educação Nacional (LDBEN), Lei no 9.394/2016 (Brasil, 1996), que reconheceu o Ensino Médio como etapa final da Educação Básica, ocorreu dentro dessa lógica, apesar das resistências sociais e das lutas organizadas assegurarem alguns ganhos.

Bertoldo (2018) destacou a integração entre educação geral e profissional na LDBEN n ${ }^{\circ}$ 9.394/1996, pois o Art. 36 define que o aluno, no Ensino Médio, será preparado para o exercício do trabalho. Seu Art. 40 estipula que a Educação Regular e a Profissional estarão articuladas. Neves e Pronko (2008) destacam, todavia, que essa lei introduziu a modalidade escolar chamada Educação Profissional, e que esta se voltava à formação do trabalhador polivalente.

As reformas posteriores afetaram a possibilidade de integração na formação das juventudes brasileiras. O Decreto n ${ }^{\circ}$ 2.208, promulgado em 1997 (Brasil, 1997), contrariou o que fora determinado pela LDBEN. Determinou, no Art. 5º que a Educação Profissional seria desarticulada do Ensino Regular e teria sua própria organização curricular. Passou-se, assim, a ofertar o Ensino Médio de duas formas: a subsequente e a concomitante.

Essa lei foi alvo de muitas resistências e polêmicas, pois reforçava ainda mais a desigualdade educacional existente. Ela só foi revogada com a promulgação do Decreto $\mathrm{n}^{\circ}$ 5.154, em 2004 (Brasil, 2004). A posse de Luiz Inácio Lula da Silva na presidência (2003-2011) proporcionou uma nova ênfase no Ensino Profissional, que passou a ser integrado ao Ensino Médio, mantendo, no entanto, as modalidades concomitante e subsequente. Ele "se fundamentava na perspectiva de uma formação profissional integrada à formação geral nos seus múltiplos aspectos humanísticos e científicos tecnológicos” (Bertoldo, 2018, p. 04). Ferreira (2017, p. 299) argumenta que “a perspectiva era desenvolver uma política educacional com 
Neide de Almeida Lança Galvão Favaro, Priscila Semzezem, Cleissiane Aguido Gotardo

vistas ao aumento da escolarização dos jovens e adultos e a melhoria da qualidade da formação do trabalhador".

Essa tentativa de integração, cujos efeitos não foram os desejados pelos educadores progressistas envolvidos, foi desarticulada com a Reforma do Ensino Médio de 2017, que se configurou como uma proposta alinhada aos interesses do capital.

Entender esse processo requer a apreensão do cenário político-econômico brasileiro, a fim de desvelar as políticas adotadas neste início de século. A partir do ano de 2016, o Brasil “entra em uma nova fase da contrarrevolução preventiva e prolongada, conduzida pelas frações mais agressivas e conservadoras da burguesia" (Lima, 2019, p. 517), aprofundando as proposições restritivas em relação às políticas sociais, o que acirrou a destituição dos direitos conquistados historicamente pela classe trabalhadora. Dentre as ações que compõem este rol, está a Reforma do Ensino Médio, de 2017.

Lima (2019) destaca que a entrada do Governo Temer (2016-2019) foi marcada pela elaboração de documentos e medidas legais que subsidiaram a efetivação das políticas adotadas, sendo eles: I) Uma Ponte para o Futuro (Fundação Ulysses Guimarães \& Partido do Movimento Democrático Brasileiro, 2015); II) Emenda Constitucional $\mathrm{n}^{\circ}$ 95, promulgada em 15 de dezembro de 2016; e III) A Travessia Social: uma ponte para o futuro (Fundação Ulysses Guimarães \& Partido do Movimento Democrático Brasileiro, 2016).

Os documentos descrevem as diretrizes do governo para os programas sociais e para a política de educação, com destaque para A Travessia Social: uma ponte para o futuro. É visível, em sua plataforma, a gestão e a configuração da Reforma do Ensino Médio:

$\mathrm{O}$ ensino de $2^{\circ}$ grau no Brasil precisa de uma reforma completa. A estruturação dos currículos pressupõe exclusivamente uma preparação genérica para o ensino superior. $\mathrm{O}$ aproveitamento final é muito pequeno. A conclusão desta etapa não habilita o aluno para coisa alguma, a não ser os exames de ingresso na Universidade, embora se saiba que a maioria dos alunos encerra aí sua formação escolar (Fundação Ulysses Guimarães \& Partido do Movimento Democrático Brasileiro, 2016, p. 15).

Segundo Lima (2019), este documento aponta um direcionamento político e econômico alinhado aos ditames dos organismos internacionais, reforçando a condição de subalternidade do país na divisão internacional do trabalho. Destaca-se que o atual governo, de Jair Messias Bolsonaro (2019-), não só dá continuidade como aprofunda os ataques às políticas sociais e de 
educação. Trata-se, conforme Hillesheim e Garcia (2019, p. 487), de "um mix que alinha os interesses do empresariado educacional com preceitos religiosos que visa, simultaneamente, tornar a educação uma mercadoria ainda mais rentável”.

Cabe considerar ainda que, na lógica de destinar o orçamento ao pagamento da dívida pública, para operar o capital financeiro, a execução orçamentária do último ano, de 2019, revelou a menor porcentagem destinada à política de educação no Brasil, desde o ano de 2013, conforme expressa a Tabela 1:

Tabela 1. Execução Orçamentária - Educação Brasileira: 2013-2019

\begin{tabular}{ccc}
\hline ANO & $\begin{array}{c}\text { ORÇAMENTO EXECUTADO } \\
(\mathbf{R} \$)\end{array}$ & $\begin{array}{c}\text { EXECUÇÃO EDUCAÇÃO } \\
(\%)\end{array}$ \\
\hline 2013 & 1,783 Trilhões & 3,70 \\
2014 & 2,168 Trilhões & 3,73 \\
2015 & 2,268 Trilhões & 3,91 \\
2016 & 2,572 Trilhões & 3,70 \\
2017 & 2,483 Trilhões & 4,10 \\
2018 & 2,621 Trilhões & 3,62 \\
2019 & 2,711 Trilhões & 3,48 \\
\hline
\end{tabular}

Fonte: Tabela sistematizada pelas autoras (Auditoria Cidadã da Dívida, 2019, 2020).

No âmago desta lógica política e econômica, o orçamento da Educação Básica no último ano sofreu um corte de $33 \%$ na alocação do "Dinheiro Direto na Escola para a Educação Básica". Este programa é responsável pela assistência financeira, a fim de propiciar melhorias na infraestrutura física e pedagógica, por isso tal redução inviabiliza avanços no ensino, bem como deteriora os espaços públicos de acesso à educação (Félix, 2019).

Evidencia-se, ainda, o papel fundamental do Estado para a operacionalização dos ajustes em outras esferas, como na regulamentação da flexibilização do trabalho, por exemplo, viabilizada na Reforma Trabalhista, Lei no 13.467/2017 (Brasil, 2017b). O projeto adotado 
revela que a manutenção do padrão dependente de desenvolvimento associado ao padrão dual de expropriação do excedente econômico e ao padrão compósito de hegemonia burguesa está expressa nas concepções do papel do Brasil na economia mundial como exportador de commodities minerais e agrícolas e do Estado como condutor do arcabouço jurídico que opera a contrarreforma trabalhista e a revisão do sistema tributário, de forma a atender aos interesses econômicos de parceiros privados internacionais e locais (Lima, 2019, p. 518).

Ao analisar o direcionamento das ações do governo, por intermédio dos documentos que o orientam, a autora chama a atenção para o fato de que esse movimento:

evidencia os novos contornos da luta de classes no Brasil na atual fase da contrarrevolução neoliberal, denotando a natureza ultraconservadora da burguesia brasileira e suas ações antissociais e antinacionais de exploração crescente da força de trabalho; de exportação de parte do excedente econômico para os centros imperialistas; de privilegiamento dos setores privados e de intensificação das desigualdades econômicas, políticas e sociais (Lima, 2019, p. 518).

Na esteira das Reformas do Ensino Médio e Trabalhista, em 13 de novembro de 2019 foi aprovada a Reforma Previdenciária, pela Emenda Constitucional nº 103 (Brasil, 2019), que altera o regime de contribuições e benefícios. A sua justificativa "está calcada no mito do seu déficit”, conforme apontam Lourenço, Lacaz e Goulart (2017, p. 481). Ao desvelar seus reais objetivos, constata-se que a Reforma da Previdência Social se fundamenta na relação da mercadorização dos direitos. Os direitos sociais ingressam no processo de valorização pois, conforme Lara e Maranhão (2019, p. 56-57), “as privatizações, as contrarreformas nas políticas sociais, são fenômenos de um mesmo processo socioeconômico que demonstra a crise generalizada e duradoura da produção e reprodução social capitalista".

Esse conjunto de ações faz parte das estratégias de recuperação do capital, diante das suas contradições internas, e afeta diretamente a classe trabalhadora. Ela se vê ameaçada em sua existência, tanto pela situação de desemprego quanto pela condição atual de sua exploração no trabalho. Esta se dá de forma complexa e contraditória, no atual estágio do capital: 
O decremento e a eliminação do uso da força de trabalho, causados pelo aumento das forças produtivas, têm como efeito uma diminuição da parte variável do capital em relação à parte constante, ou seja, cai, relativamente, a quantidade de trabalhadores a ser explorados. Como somente a força de trabalho, que constitui o capital variável, produz mais-valia, sua diminuição em relação ao capital constante provoca uma tendencial redução da taxa de lucro, mesmo que aumente a taxa de maisvalia com o incremento do grau de exploração ocasionado pela maisvalia relativa, o que obriga os capitalistas, como forma de compensação, a prolongar a jornada de trabalho, caracterizando a extração de maisvalia absoluta. Dessa forma, por causa das contradições inerentes à acumulação, a criação das condições de extração de mais-valia relativa gera, ao mesmo tempo, a necessidade de mais-valia absoluta, redundando na combinação de exploração dessas duas modalidades de mais-valia (Tumolo, 2017, p. 610).

É este o processo em curso, que só pode ser apreendido em suas causas ao considerar as relações produtivas que o sustentam. No caso da Reforma do Ensino Médio em vigor, a compreensão dos seus objetivos requer sua articulação a esse processo mais amplo, de valorização do capital no estágio atual.

\section{Reforma Brasileira do Ensino Médio de 2017: Objetivos e Consequências}

Proposta pelo Ministério da Educação (MEC), a atual reforma defende a flexibilização do currículo do Ensino Médio, propagando assegurar que o aluno opte pelo aprofundamento em uma área, ou pela sua formação profissional. O processo de sua aprovação, com a Lei $\mathrm{n}^{\circ}$ 13.415/2017 (Brasil, 2017a), evidenciou a disputa entre dois projetos diferentes para esse nível de ensino: de um lado o dos grupos empresariais e representantes do MEC, e de outro, o dos educadores e defensores da educação pública.

A Lei $n^{\circ} 13.415 / 2017$ alterou dispositivos da LDBEN, afetando diversos aspectos do Ensino Médio como, por exemplo, a carga horária. O Art. 13 sugere um ensino de tempo integral: "fica instituída, no âmbito do Ministério da Educação, a Política de Fomento à Implementação de Escolas de Ensino Médio em Tempo Integral” (Brasil, 2017a). As condições precárias das escolas brasileiras, entretanto, tendem a se agravar, tendo em vista a atual diminuição de recursos financeiros. Além disto, muitos estudantes de escolas públicas são trabalhadores e estudam à noite, o que torna inviável integralidade para todos. Esta aparente incoerência é superada na análise dos dispositivos mais amplos da Lei, pois o ensino integral não se estenderá a todas as escolas. 
Neide de Almeida Lança Galvão Favaro, Priscila Semzezem, Cleissiane Aguido Gotardo

No interior da lógica flexível, a Lei nº 13.415 reformula o currículo do Ensino Médio. Ela estabelece uma Base Nacional Comum Curricular (BNCC), dividida em áreas do conhecimento, em que apenas as disciplinas de matemática e português serão obrigatórias nos três anos do Ensino Médio, pois as demais ficam diluídas em "estudos e práticas”, conforme $\S$ $2^{\circ}$ do Artigo 35-A (Brasil, 2017a). Além disso, ao lado da BNCC, o currículo do Ensino Médio é composto por cinco "itinerários formativos": linguagens e suas tecnologias; matemática e suas tecnologias; ciências da natureza e suas tecnologias; ciências humanas e sociais aplicadas; e formação técnica e profissional.

Os apologistas da reforma alegam que, assim, o aluno poderá escolher qual itinerário deseja seguir. Tendo em vista a fragilidade atual das instituições públicas de ensino, prevê-se que não há condições de equipar laboratórios ou de implantar tecnologias para ofertar todos os itinerários, nem haverá professores qualificados nas distintas áreas de conhecimento. $\mathrm{Na}$ realidade, a Lei é cristalina: o Artigo 36 estabelece que os itinerários formativos "deverão ser organizados por meio da oferta de diferentes arranjos curriculares, conforme a relevância para o contexto local e a possibilidade dos sistemas de ensino" (Brasil, 2017a).

Caberá, portanto, aos sistemas de ensino definir quais e quantos itinerários formativos ofertar, tendo em vista os profissionais, os materiais e as tecnologias necessárias de que dispõem. O resultado é o aprofundamento da desigualdade nas oportunidades de conhecimento para as juventudes brasileiras, tendo em vista as distintas condições das escolas e dos estados.

Para agravar esse quadro, orientada pela lógica neoliberal, a reforma propicia a redução de investimentos para a educação, pois, “para economizar dinheiro, o Poder Público ofertará menos conteúdos obrigatórios aos estudantes e, consequentemente, contratará menos professores para lecionar" (CNTE, 2018, p. 416).

O caráter mistificador do ensino integral é desmascarado em suas intenções. É estabelecido, no $\S 5^{\circ}$ do Artigo 35-A, que "a carga horária destinada ao cumprimento da Base Nacional Comum Curricular não poderá ser superior a mil e oitocentas horas do total da carga horária do ensino médio, de acordo com a definição dos sistemas de ensino" (BRASIL, 2017a).

Ao analisar as proposições iniciais para a carga horária do Ensino Médio, houve uma forte resistência da comunidade educacional, que alertou que a parte comum da formação curricular estaria "condicionada a 1.800 horas de uma etapa escolar prevista para alcançar 4.200 horas em 2022” (CNTE, 2018, p. 416), o que significaria que o exigido na BNCC do Ensino 
Médio corresponderia "a menos da metade da carga horária geral" (CNTE, 2018, p. 416). Na regulamentação deste aspecto, ficou determinado que o Ensino Médio deve atingir a carga horária máxima de 3.000 horas até 2022 (Brasil, 2018), mas permaneceu o dispositivo que retringe a duração máxima dos conteúdos comuns a 1.800 horas, o que permite certa autonomia para as escolas apresentarem uma carga horária ainda menor.

Dentre seus efeitos perversos para a formação dos estudantes, vislumbra-se a delimitação dos conteúdos, a depender do total de horas estabelecido. O que se conclui é que os centros de poder do capital conformam o Ensino Médio à sua lógica, a fỉm de assumir, assim, a direção intelectual e moral das juventudes trabalhadoras.

A publicidade em torno da Base Nacional Curricular Comum (BNCC) é uma forma de eclipsar o fato de que, objetivamente, com a reforma do Ensino Médio (BRASIL, 2017a), os cinco itinerários possíveis denotam percursos escolares distintos, negando o fortalecimento do que é o comum na educação básica. Como poucas escolas conseguirão assegurar os itinerários com maior presença das áreas das ciências da natureza e de matemática, possivelmente restarão itinerários cada vez mais centrados na profissionalização precária e em conformidade com a cadeia produtiva local ou mais funcional aos orçamentos da rede de ensino, desmantelando a ode da 'livre escolha' dos estudantes (Motta, Leher \& Gawryszewski, 2018, p. 320, grifo dos autores).

Além da parte comum curricular da formação estar limitada a 1.800 horas, no caso da formação técnica e profissional, conforme $\S 6^{\circ}$ do Artigo 36 (Brasil, 2017a), o restante da carga horária poderá considerar outros ambientes formativos que sejam certificados e também vivências práticas no setor produtivo.

O Ensino Profissional, desta forma, volta ao debate, pois a reforma apresenta um formato pedagógico caracterizado pelo aprofundamento da desigualdade educacional, em que o currículo escolar fica regulado pelo setor produtivo. Deste modo, a "formação técnica de baixa qualidade (cursos de qualificação profissional, tipo eletricista, estética corporal, entre outros) caminha na direção de um verdadeiro apartheid educacional” (CNTE, 2018, p. 418).

Embora aparente uma igualdade de oportunidades, na prática, a deficiência na formação em determinadas áreas beneficiará a iniciativa privada, abrindo outros nichos de mercado para a complementação da formação como, por exemplo, cursos preparatórios, presenciais e a distância, além de materiais didáticos. 
Neide de Almeida Lança Galvão Favaro, Priscila Semzezem, Cleissiane Aguido Gotardo

Outro aspecto a ser problematizado na reforma do Ensino Médio e que está relacionado diretamente com sua flexibilização, é a ampliação dos meios e dos ambientes formativos. A carga horária e a formação exigida no Ensino Médio poderão ser complementadas por intermédio das Parcerias Público-Privadas (PPP).

No $§ 11$ do Artigo 36 da Lei no 13.415 (Brasil, 2017a), consta que, para o “cumprimento das exigências curriculares do ensino médio, os sistemas de ensino poderão reconhecer competências e firmar convênios com instituições de educação a distância com notório reconhecimento". Na Resolução n 03/2018, que "Atualiza as Diretrizes Curriculares Nacionais para o Ensino Médio” (Brasil, 2018), fica estipulado que as atividades a distância podem contemplar até 20 (vinte) \% da carga horária total do Ensino Médio, aumentando em até 80\% no caso da Educação de Jovens e Adultos (EJA).

Ao se considerarem os dados da realidade concreta brasileira, fica evidente a dificuldade de assegurar uma educação pública de qualidade com a adoção da educação a distância (EAD). É preciso considerar que o "acesso à internet" das famílias brasileiras é precário. O levantamento realizado pelo Instituto Brasileiro de Geografia e Estatística (IBGE), na Pesquisa Nacional por Amostra de Domicílios (PNAD), em 2016 (IBGE, 2018), demonstrou que, no Brasil, dentre as pessoas com mais de dez anos que acessaram a internet, 94,2\% foi para trocar mensagens e 94,6\% dos usuários nessa faixa etária se conectaram via celular. Sobre os que não acessaram a internet, um total de 63,4 milhões de pessoas pesquisadas, as justificativas foram: falta de interesse $(37,6 \%)$, serviço de acesso caro $(14,3 \%)$, e não sabiam usar $(37,8 \%)$.

Nas residências que possuíam acesso à internet, uma parcela de 69,3\% do total de 48,1 milhões, o celular foi o único equipamento usado para 38,6\% delas utilizá-la. Já o acesso pelo computador foi de apenas $2,3 \%$ das famílias com internet, mesmo ele estando presente em mais da metade $(57,8 \%)$ desses domicílios. Especificamente, chama a atenção o acesso dos estudantes à internet. Em um universo de 37,2 milhões de estudantes com 10 anos ou mais, 81,2\% utilizaram-na. No que se refere aos estudantes da rede pública, 75,0\% deles acessaram a internet, em contraste com $97,4 \%$ dos alunos da rede privada. A utilização da internet entre os pesquisados aumentou de acordo com o nível de instrução: sem instrução $(11,2 \%)$, fundamental incompleto $(43,6 \%)$, superior incompleto $(97,1 \%)$ e superior completo $(95,7 \%)$.

Os dados revelam que um número significativo de famílias e estudantes ainda não possuem acesso à internet no Brasil, principalmente os alunos da educação pública. Desta forma, 
a proposta que prevê a possibilidade de cumprimento de uma percentagem de horas do currículo na modalidade a distância, será extremamente prejudicial a esses estudantes, limitando seu direito ao ensino. O que se constata é que esse projeto não está interessado na melhoria da educação pública, mas atende aos objetivos do mercado, em que prevalece a busca de lucro, inclusive por intermédio de recursos públicos. Expressa-se assim, também por esta via, a viabilização da conversão da educação em um produtivo mercado e, consequentemente, sua privatização e subsunção ao capital.

$\mathrm{Na}$ educação, a mercantil-filantropia adentra ferozmente aos fundos públicos por meio de parcerias, consórcios e mercantilização de suas mercadorias. Capitalizado o ensino superior, agora, o radar dos investidores e das grandes corporações do ramo educativo volta-se para Ensino Médio, a exemplo dos grupos Kroton, 12 SEB e Ser Educacional (Motta, Leher \& Gawryszewski, 2018, p. 319).

A CNTE (2018) corrobora com tal constatação, de que o Estado brasileiro direciona o Ensino Médio à privatização, por meio das PPP. Esta forma de terceirização tende a fragmentar ainda mais a educação pública e a inviabilizar a possibilidade de uma formação humana ampla, tendo em vista que o seu objetivo está diretamente voltado para atender às demandas do mercado capitalista. As PPP consistem em "uma conexão que esvaziará as instituições públicas de maiores investimentos em infraestrutura física e humana, dificultando a universalização ou expansão do ensino médio em instituições de ensino público, gratuito e de qualidade" (Costa \& Coutinho, 2018, p. 1647). O propalado ensino de tempo integral da reforma em vigor revela sua verdadeira face, ao permitir que parte do Ensino Médio seja efetivado fora da escola, abrindose à sua mercantilização e também, no caso da formação técnica e profissional, à possibilidade de exploração precoce da força de trabalho do estudante.

A pedagogia do capital acena com a falsa promessa de uma ocupação certa nos postos de trabalho, desde que o jovem estudante invista em sua formação, acionando, para isto, as ideologias da empregabilidade e do empreendedorismo. Segundo Motta, Leher e Gawryszewski (2018, p. 317, grifos dos autores), "trata-se de educar, ao seu modo, essa massa de jovens trabalhadores, qualificados ou não, para as adversidades que o mercado impõe e manter as condições políticas e sociais necessárias para a reprodução ampliada do capital”.

Outro dispositivo que merece reflexão é a implantação do notório saber. A Lei $\mathrm{n}^{\circ}$ 13.415/2017 permite a qualquer cidadão, independente do seu nível e grau de formação, desde que comprove o seu saber, ser professor em cursos de Educação Profissional. Isto reforça a 
desqualificação da docência e afeta diretamente a qualidade da formação a ser ofertada nos cursos técnicos e profissionais de nível médio. Para Costa e Coutinho (2018), é agravada a condição educacional, ao não se propiciar aos estudantes uma formação que lhes capacite a interagir criticamente com os contextos sociopolíticos, econômicos e culturais.

De fato, este conhecimento não se encontra presente na agenda do capital, pois a formação do jovem passa a ser direcionada para a adequação social e política da força de trabalho, diante da intensificação de sua exploração, da precarização das condições de trabalho e do aumento do desemprego. Sob a perspectiva da pedagogia do capital:

os jovens necessitariam ser contemplados com um projeto formativo em que se desenvolvam competências técnicas específicas para o século XXI, de forma a delinear perspectivas e tomar 'boas decisões' acerca do seu 'projeto de vida', fortalecendo competências 'socioemocionais' relacionadas a valores morais (filtrados pelos fundamentalistas da Escola Sem Partido e pela bancada evangélica) e procedimentos comportamentais, tais como resiliência, adaptabilidade e persistência (Motta, Leher \& Gawryszewski, 2018, p. 320).

A repercussão na formação dos professores avança com intensidade, afastando a função das universidades públicas neste setor, tendo em vista que os organismos internacionais impelem a incorporação das novas tecnologias na educação, por intermédio de condicionalidades para a concessão de recursos. As tecnologias e a EAD passam a ocupar o lugar dos professores, veiculando um novo paradigma educacional.

Esse paradigma é constituído pela substituição tecnológica e pela racionalidade instrumental, está inscrito na 'flexibilização', especialmente na precarização do trabalho docente, sendo coerente com a lógica do mercado: quanto maior a presença da tecnologia, menor a necessidade do trabalho humano. Em outras palavras, prevê cada vez menos professores e mais alunos, sob a alegação de que o desempenho dos últimos depende menos da formação dos primeiros e mais dos materiais utilizados (Barreto, 2004, p. 1189, grifo da autora).

Motta, Leher e Gawryszewski (2018, p. 321-322) identificam que a formação docente é esvaziada, "sempre no sentido de uma formação desidratada de teoria e baseada em práticas balizadas no empirismo vulgar - afinal, o que é dado a pensar será assegurado pelas corporações, centros de pensamento do capital e pelas coalizões dos setores dominantes".

Estes fatores estão voltados para o atendimento das demandas de acumulação do capital frente às crises econômicas, consistindo em uma estratégia de mercantilização do ensino. O 
resultado é uma formação superficial, para a adaptação emocional e a qualificação instrumental, a fim de atender às demandas sociais e produtivas imediatas.

Esses fatos reforçam a compreensão de como a contrareforma do ensino médio é parte integrante de uma agenda globalmente estruturada da educação. Os exemplos utilizados pelos defensores dessas mudanças são frágeis, mas confirmam os padrões de governança internacional, cuja missão modernizadora é reduzir a educação (e o conhecimento) a funções mínimas de acordo com as necessidades imediatas da sociedade capitalista contemporânea. Tarefa essa que deverá ser cumprida crescentemente pelos mercados educacionais (Ferreira, 2017, p. 304).

$\mathrm{Na}$ atual conjuntura, não há medidas para a superação desses problemas, pois o objetivo está voltado ao capital, o que revelam as políticas neoliberais adotadas, ao diminuírem os direitos da população. Ofertar uma educação de nível médio adequada aos interesses do capital é o objetivo que se evidencia na atual Reforma do Ensino Médio. Aos trabalhadores, destina-se o ensino público flexível, a fim de assegurar sua conformação socioemocional, acenando com uma suposta empregabilidade, mesmo estando, a maioria, destinada ao fracasso, diante de uma relação social que aprofunda o desemprego e a desigualdade social.

\section{Considerações Finais}

A crise econômica mundial da década de 1970 gerou a reestruturação produtiva e a implementação do neoliberalismo. Tornou necessários, por conseguinte, novos processos para o disciplinamento da força de trabalho, tendo em vista as novas formas de sua exploração e a precarização de suas condições de trabalho e de existência. No Brasil, os últimos anos foram expressivos no que se refere ao aprofundamento de medidas que visam o consenso social em torno da concepção de mundo burguesa.

Destaca-se nessa conjuntura a fragilidade que adquire o direito à educação, uma vez que a EC 95 restringe o orçamento e fere conquistas constitucionais históricas. Uma dentre as justificativas desse processo foi que asseguraria o desenvolvimento econômico do país, o que se revelou "uma falácia", já que os dados do PIB de 2019 contradizem tal expectativa, indicando uma ínfima porcentagem de crescimento, em um cenário de crise global. Os resultados concretos não demonstram melhorias na qualidade de vida da maioria da população, ao contrário, são perversos para a classe trabalhadora, pois acirram-se as desigualdades, aprofunda-se a precarização do trabalho e o desemprego, dentre outros. 
Neide de Almeida Lança Galvão Favaro, Priscila Semzezem, Cleissiane Aguido Gotardo

Em específico, a Reforma do Ensino Médio brasileiro, de 2017, orientada pela lógica da flexibilidade, alterou sua estrutura e currículo. Trata-se de uma ação consolidada pelas classes dominantes para atender à lógica do capital monopolista na atual fase. Ela volta-se à formação de indivíduos flexíveis, por meio da oferta de uma educação precarizada e fragmentada, viabilizando a mercantilização da educação pública.

O Ensino Médio abre-se para a iniciativa privada por intermédio das PPP e das possibilidades de cumprimento da carga horária em outros ambientes formativos e de trabalho. A reforma incita os estudantes a não frequentarem a escola, fomentando a EAD, desconsiderando que grande parte deles não tem acesso à internet. Além disso, admite o notório saber para a docência, dispensando o trabalho qualificado do professor no ensino e no aprendizado.

A precarização da educação pública aumenta e o Ensino Médio é subsumido ao capital, a fim de atender ao modelo de produção imposto no cenário contemporâneo, que dispensa uma formação qualificada e integral para a maioria dos trabalhadores e para os prováveis futuros desempregados. As consequências são nefastas para as juventudes trabalhadoras, pois o projeto em vigor é de uma educação que não prioriza a formação humana. Suas perspectivas em relação ao trabalho são as de piores condições em termos de acesso à proteção social, que também está sendo mercantilizada. Com a Reforma da Previdência Social, também não há previsão de se assegurar renda e sobrevivência na velhice.

Destaca-se o papel do Estado em criar todo o arcabouço de leis e ações para legitimar o status quo e assegurar as taxas de lucro ao capital. O Estado se desembaraça de suas funções para com o ensino público, que se converte em uma mercadoria, abrindo-se para a iniciativa privada, efetivando sua face de atrelamento ao capital.

Em face do exposto, infere-se que, no Brasil, a atual Reforma do Ensino Médio adequou a formação dos trabalhadores aos interesses de expansão do capital, em um momento de ultraconservadorismo político e ideológico e de subordinação do país na divisão internacional do trabalho. Isto reverbera na persistência e no aprofundamento das ambiguidades formativas e na degradação da formação e da vida humana.

Entender a Lei $\mathrm{n}^{\circ}$ 13.415/2017 (Brasil, 2017a) requereu situá-la na totalidade que constitui a relação social do capital, no interior da qual ela constitui uma dentre as ações voltadas ao controle, à conformação social e à mercantilização da educação. Tal lógica não se viabiliza 
sem resistências sociais, que geram contradições e lutas genuínas em prol de outra educação. Nessa dinâmica, é essencial para todos que advogam uma educação pública, de qualidade, gratuita e comprometida com uma formação humana ampla, compreender a complexa relação social do capital em suas contradições. A educação que se almeja é a integral, omnilateral, mas isto implica a adesão a embates mais profundos, a fim de superar a sociabilidade do capital que a reprime.

\section{Referências}

Auditoria Cidadã da Dívida. (2019). Gráficos 2011- 2018. Consulta 07 de março de 2020. https://auditoriacidada.org.br/categoria-conteudo/graficos/.

Auditoria Cidadã da Dívida. (2020). Orçamento Federal Executado (pago) em $2019=\mathrm{R} \$ 2,711$ trilhões. Consulta 30 de março de 2020. https://auditoriacidada.org.br/wpcontent/uploads/2020/02/Orc\%CC\%A7amento-2019-versao-final.pdf.

Barreto, Raquel Goulart. (2004). Tecnologia e educação: trabalho e formação docente. Educ. Soc., vol. 25 (n. 8), 1181-1201. http://www.scielo.br/pdf/es/v25n89/22617.pdf.

Bertoldo, Edna. (2018). A dualidade estrutural na reforma do ensino médio. Gesto Debate, v. 06 (n. 01), 01-06. https://docplayer.com.br/112748577-A-dualidade-estrutural-na-reformado-ensino-medio.html.

Brasil. (1996, 23 dezembro). Lei $n^{\circ}$ 9.394, de 20 de dezembro de 1996. Estabelece as Diretrizes e Bases da Educação Nacional. Brasília, DF. http://www.planalto.gov.br/ccivil_03/Leis/L9394.htm.

Brasil. (1997, 17 abril). Decreto $n^{\circ}$ 2.208, de 17 de abril de 1997. Regulamenta o $§ 2^{\circ}$ do art. 36 e os arts. 39 a 42 da Lei $n^{\circ} 9.394$, de 20 de dezembro de 1996, que estabelece as diretrizes e bases da educação nacional - revogado. Brasília, DF. http://www.planalto.gov.br/ccivil_03/decreto/D2208.htm.

Brasil. (2004, 23 julho). Decreto $n^{\circ}$ 5.154, de 23 de julho de 2004. Regulamenta o $\S 2^{\circ}$ do art. 36 e os arts. 39 a 41 da Lei ${ }^{\circ} 9.394$, de 20 de dezembro de 1996, que estabelece as diretrizes e bases da educação nacional, e dá outras providências. Brasília, DF. http://www.planalto.gov.br/ccivil_03/_Ato2004-006/2004/Decreto/D5154.htm\#art9.

Brasil. (2017a, 17 fevereiro). Lei $n^{o} 13.415 / 2017$, de 16 de fevereiro de 2017. Altera as Lei $\mathrm{n}^{\circ}$ 9.394, de 20 de dezembro de 1996 e institui a Política de Fomento à Implementação de Escolas de Ensino Médio em Tempo Integral. Brasília, DF.http://www.planalto.gov.br/ccivil_03/_ato2015-2018/2017/lei/L13415.htm.

Brasil. (2017b, 13 julho). Lei $n^{\circ} 13.467$ de 13 de julho de 2017. Altera a Consolidação das Leis do Trabalho (CLT), aprovada pelo Decreto-Lei no 5.452, de 1o de maio de 1943, e as Leis nos 6.019, de 3 de janeiro de 1974, 8.036, de 11 de maio de 1990, e 8.212, de 24 de julho de 1991, a fim de adequar a legislação às novas relações de trabalho. Brasília, DF. http://www.normaslegais.com.br/legislacao/Lei-13467-2017.htm. 
Neide de Almeida Lança Galvão Favaro, Priscila Semzezem, Cleissiane Aguido Gotardo

Brasil. (2018, 21 novembro). Resolução CNE/CEB $n^{o}$ 3, de 21 de novembro de 2018. Atualiza as Diretrizes Curriculares Nacionais para o Ensino Médio. Brasília, DF. http://novoensinomedio.mec.gov.br/resources/downloads/pdf/dcnem.pdf.

Brasil. (2019, 12 novembro). Emenda Constitucional $n^{\circ} 103$ de 12 de novembro de 2019. Altera o sistema de previdência social e estabelece regras de transição e disposições transitórias. Brasília, DF. http://www.normaslegais.com.br/legislacao/emendaconstitucional103.htm.

Chesnais, François. (1999). Tobin ou not Tobin?. São Paulo: Ed. UNESP.

Chesnais, François. (2005). O capital portador de juros: Acumulação, internacionalização, efeitos econômicos e políticos. Chesnais, François (org.). A finança mundializada: raízes sociais e políticas, configuração, consequências, 35-68 São Paulo: Boitempo.

Confederação Nacional dos Trabalhadores em Educação - CNTE. (2018). Consequências práticas da BNCC e da reforma do ensino médio. Rev. Retratos da Escola, v. 12 (n. 23), 413-425. http://retratosdaescola.emnuvens.com.br/rde/article/viewFile/901/pdf.

Costa, M. A., \& Coutinho E. H. L. (2018). Educação profissional e a reforma do ensino médio: Lei $\mathrm{n}^{\circ}$ 13.415/2017. Educação \& Realidade, v. 43 (n. 4), 1633-1652. http://www.scielo.br/scielo.php?script=sci_arttext\&pid=S2175-62362018000401633.

Cucolo, E., \& Pamplona, N. (2020, março 04). PIB do Brasil cresce 1,1\% em 2019, diz IBGE; resultado é menos da metade do projetado no início do ano. Folha de São Paulo. Consulta 28 de março de 2020. https://www1.folha.uol.com.br/mercado/2020/03/pib-do-brasilcresce-11-em-2019-diz-ibge.shtml.

Félix, Rosana. (2019, Dezembro 25) "Gasto com educação cai desde 2015. 2019 não foi exceção". Jornal Gazeta do Povo. Consulta 04 de março de 2020. https://www.gazetadopovo.com.br/educacao/gasto-com-educacao-cai-desde-2015-2019nao-foi-excecao/\#ancora-1.

Ferreira, Eliza Bartolozzi. (2017). A contrarreforma do ensino médio no contexto da nova ordem e progresso. Educ. Soc., v. 38 (n. 139), 293-308. http://www.scielo.br/pdf/es/v38n139/16784626-es-38-139-00293.pdf.

Fundação Ulysses Guimarães, Partido do Movimento Democrático Brasileiro. (2016). A travessia social: uma ponte para o futuro. Brasília, Fundação Ulysses Guimarães. https://www.fundacaoulysses.org.br/wpcontent/uploads/2016/11/TRAVESSIA-SOCIALPMDB_LIVRETO_PNTE_PARA_O_FUTURO.pdf.

Fundação Ulysses Guimarães, Partido do Movimento Democrático Brasileiro. (2015). Uma ponte para o futuro. Brasília: Fundação Ulysses Guimaraes. https://www.fundacaoulysses.org.br/wp-content/uploads/2016/11/UMA-PONTE-PARAO-FUTURO.pdf.

Gounet, Thomas. (1999). Fordismo e toyotismo na civilização do automóvel. São Paulo: Boitempo.

Harvey, David. (2008). O neoliberalismo: história e implicações. 13. ed. São Paulo: Loyola.

Hillesheim, J., \& Garcia, A. V. (2019). Educação e trabalho no Brasil: a perspectiva defendida pelo capital para a formação dos trabalhadores. R. Katál, v. 22 (n. 3), 479-490. http://www.scielo.br/pdf/rk/v22n3/pt_1982-0259-rk-22-03-491.pdf. 
Instituto Brasileiro de Geografia e Estatística - IBGE. (2018). PNAD Contínua TIC 2016: 94,2\% das pessoas que utilizaram a Internet o fizeram para trocar mensagens. Agência IBGE Notícias. Consulta 08 de março de 2020. https://agenciadenoticias.ibge.gov.br/agencia-salade-imprensa/2013-agencia-de-noticias/releases/20073-pnad-continua-tic-2016-94-2-daspessoas-que-utilizaram-a-internet-o-fizeram-para-trocar-mensagens.

Lara, R., \& Maranhão, C. (2019). Fundamentos do trabalho, "questão social” e Serviço Social. Souza, E. Â. de S. Silva, M. L. de O. (orgs). Trabalho, questão social e serviço social: a autofagia do capital. 37-60. São Paulo: Cortez.

Lima, Kátia. (2019). Educação superior em tempos de ajustes neoliberais e regressão de direitos. R. Katál., Florianópolis, v. 22 (n. 3) 513-524. http://www.scielo.br/pdf/rk/v22n3/pt_19820259-rk-22-03-525.pdf.

Lourenço, E. Â. de S., Lacaz, F. A. de C., \& Goulart, P. M. (2017). Crise do capital e o desmonte da Previdência Social no Brasil. Serviço Social e Sociedade, n. 130, 467-486. http://www.scielo.br/pdf/sssoc/n130/0101-6628-sssoc-130-0467.pdf.

Mészáros, István. (2002). Para além do capital. São Paulo, Boitempo Editorial, 2002.

Motta, V. C. da; Leher, R, \& Gawryszewski, B. (2018). A pedagogia do capital e o sentido das resistências da classe trabalhadora. Ser social: educação e lutas sociais no Brasil. v. 20 (n. 43), 310-328. https://periodicos.unb.br/index.php/SER_Social/article/view/18862/17577.

Netto, J. P., \& Braz, M. (2012). Economia Política: uma introdução crítica. 8. ed. São Paulo: Cortez.

Neves, L. M. W., \& Pronko, M. A. (2008). Configuração histórica e mudanças da formação para o trabalho complexo no Brasil contemporâneo. Rio de Janeiro: EPSJV.

Tumolo, Paulo Sérgio. (2003). Trabalho, vida social e capital na virada do milênio: apontamentos de interpretação. Educ. Soc.vol. 24 (n. 82), 159-178. http://www.scielo.br/pdf/es/v24n82/a07v24n82.pdf

Tumolo, Paulo Sérgio. (2017). A atual configuração capitalista na periferia do sistema: contribuições teóricas para um debate. Perspectiva. v. 35 (n. 2), 598-614. https://periodicos.ufsc.br/index.php/perspectiva/article/view/2175-795X.2017v35n2p598.

Tumolo, Paulo. Sérgio. (2002). Da contestação à conformação. A formação sindical da CUT e a reestruturação capitalista. Campinas, SP: Editora da UNICAMP.

Zibas, Dagmar Maria Leopoldi. (2005). A reforma do ensino médio nos anos de 1990: o parto da montanha e as novas perspectivas. Revista Brasileira de Educação, n. 28, 24-36. http://www.scielo.br/pdf/rbedu/n28/a03n28.pdf. 